\title{
Dreaming of Colonialism: Imagining "Place” in Richard Brome's The Antipodes
}

\author{
Matthew Hetu*
}

\begin{abstract}
This article explores the colonial mindset behind the depiction of space and travel in Richard Brome's The Antipodes. Using Benedict Anderson's Imagined Communities and Robert T. Tally Jr.'s "On Literary Cartography: Narrative as a Spatially Symbolic Act" as frames for reading travel and travel literature in the text offers new insight into reading Antipodes' underlying colonial mindset that is intertwined with the complex metatheatrical elements of the play. I read Peregrine as a British explorer going into the exotic to reform and impose his own ways of knowing onto the people of the Antipodes. However, the complex metatheatrical elements further complicates this colonial reading of the text. The text uses metatheatrical elements that ultimately make the audience aware of their own role in the space of the play-invoking a sense of self reflection. By focusing on the ways in which the exotic world is constructed and imagined, the nation as a performance, and the colonial discourse and power dynamics underlying the text I argue that The Antipodes can be read through modern literary theory to better understand and display the emerging difficulties and problems that accompany the developing sense of English nationalism and proto-colonialism. In doing so, the text displays the inherent colonial structures that inform and limit the role of both travel literature and the romance genre in "imaging" nations-something that is pivotal to both questioning and understanding the role of the nation in an increasingly global context.
\end{abstract}

Keywords: metatheatre, colonialism, travel, nationalism, literary cartography, performance, mapping

\section{Introduction}

Richard Brome is an English playwright (c.1590-1652) whose early career has considerable connections to fellow playwright Ben Johnson-both professionally and personally. Brome is best known for his plays The Northern Lasse and $A$ Joviall Crew, but in recent scholarship, his work
The Antipodes has made a resurgence. The Antipodes will be the focus of this research. It is a comedy written in the 1640 , making it one of Brome's later works, the play offers a complex metatheatrical representation of travel and playgoing. The majority of the play follows the casts' persistent tricking of Peregrine, who is obsessively "sick" with the idea of travel, into thinking he is in the foreign land

* Department of English, College of Arts and Science, University of Saskatchewan, Saskatoon, SK, Canada

Correspondence: mrh736@usask.ca

University of Saskatchewan Undergraduate Research Journal Volume 7, Issue 2, 2021

(c) 2021 Matthew Hetu. This open access article is distributed under a Creative Commons Attribution Non-commercial 4.0 license. (https://creativecommons.org/licenses/by-nc/4.0/) 
of the Antipodes, an anti-London of sorts. Yet, in reality he is in a playhouse surrounded by people acting the part. A variety of complex side plots go on, but most importantly, is Peregrine's interactions with the "people" (who are in fact just acting) of the Antipodes, and crowning himself king over the fictitious kingdom, which for him appears to be a very real place.

To what extent then does the mapping of voyaging and travel in Brome's Antipodes reflect the reality of the Eurocentric colonial gaze of British expansion and exploration of the Early Modern Period? Using ideologies from Benedict Anderson's Imagined Communities and Robert T. Tally Jr.'s "On Literary Cartography: Narrative as a Spatially Symbolic Act" as frames for understanding travel and travel literature in the play, offers new insight into reading Antipodes' underlying colonial mindset. Anderson's texts construct a means to situate the role of travel literature within the text and its role in forming a sense of nation. Combining this discussion of nationhood with the concept of literary cartography urges the audience to become critical of, and aware of, the descriptions of "place" within the play and how this mapping of geography further complicates the role of imagining nations as well as imagining exotic spaces. Reading Peregrine as a "British" explorer going to control and reform the exotic space of the Antipodes, leads quite obviously to a discussion of colonialism and expansionism. However, the complicated metatheatrical nature of the play further complicates this reading by constructing multiple layers of audiences and plays within the text. By recognizing and exploring the role of travel from Peregrine's unaware perspective, the audience of the play within a play, and also the audience of The Antipodes in general-I argue that the text very much asks the audiences to become both aware and critical about travel and voyaging, in the real and literary worlds. By creating self-reflection in the audience, the text displays a critical attitude within an increasingly emerging sense of British expansionism and colonialism thereby creating a complex "map" of the function of voyage and travel within the emerging nation.

\section{Mapping an Imagined World}

To understand Brome's Antipodes, it is helpful to "map" out the geographical movements (or lack thereof) that take place within the text, or in other words, to engage with the practice of literary cartography. Tally Jr. argues that "mapping establishes a meaningful framework for the subject, with points of reference for thinking about oneself and one's place in the broader social space. Likewise, narratives are frequently used to make sense of, or give form to, this world in significant ways. As such, literary works serve a cartographic function by creating a figurative or allegorical representation of a social space, broadly understood" (Tally Jr. 1). Literary cartography offers more than the presentation and study of actual maps in the space, but also the way in which characters interact with and describe the spaces that they are in. Essentially, it is a field of study that asks the audience to become conscious of and critical of the "maps" of spaces the text presents and think about what these maps say about both the world of the text and the real world.

This definition of literary cartography offers a means to explore the complex webs of "maps" laid out within the metatheatrical elements of Brome's Antipodes. The most interior map being the travel undergone in Peregrine's mind. However, the idea of voyage is surrounded by the people within the play that recognize the space for what it actually is: a playhouse. Even further, there are the ways in which the plays most exterior audience (the real people watching the play) view and interact with the space of the play that also creates a distinctive "map" of the playhouse. Although Brome's work does not address the concept of colonialism directly, I argue that through reading how these metatheatrical layers see "place" within the Antipodes that the play engages intensely with changing functions and views that voyaging and travel literatures play in the Early Modern Period that comes to represent what Shankar Raman labels, "proto-colonial voyaging" (132). Descriptions of discovery are no new thing within early modern travel literature, and the initial introduction of the Antipodes is no exception: "In outward features, language and religion, resemble those to whom they are supposite... but in their manners, their carriage, and conditions of life, extremely contrary" (Brome 1.6.107-113). It is described as a place to wonder at. The Antipodes completely reverse the manners of the place "above" (note this discourse involves placing England in a superior position above the "other") them. The map painted of the Antipodes is one that is a far-fetched and awe-inspiring depiction of the exotic.

If it is print culture (i.e., newspapers are the main discussion of Imagined Communities) how does travel literature and pamphlets inside the text function as a map of the nation? The introduction to travel and voyaging in the text is not of an actual journey but secondary accounts of travel in the form of travel writing: Peregrine has "always loved to read / Reports of travels and of voyages" and been consumed with "traveling thoughts" (Brome 1.1. 131-2). So, in the frame of imagined communities, this introduction to travel offers a formative way of situating a sense of national community by presenting a "we are us" (England) because we are not them (the other) mentality. It is in the direction that many scholars view the text as a commentary on domestic politics-viewing The Antipodes as an inflated reflection on the political and social issues of the time. However, I argue that it is also a fruitful frame to discuss the role that travel narratives in both the Antipodes as a work and English society as a whole play in forming a sense of nationalism in an expanding global context and expressing the concern of remaining "English" in a global world. 
It is evident then that Peregrine's fascination with travel and voyaging is not a seeking of knowledge or travel for the sake of travel but is instead a fantasy of the exoticin the sense that he is concerned with the fantastical and inaccurate elements of travel literature-such as Mandeville's fantastical adventures that infatuate Peregrine's mind. It is in this fantastical imagining of the "other" that makes the play fascinated not with the act of voyaging in the Early Modern Period but in the reasoning behind the voyage and shows what England imagines the "other" to be like both in space and culture. It is in this vision of a nation so far removed from English culture that we see the truly restrictive manner of thinking that spurred the emerging ideology of British expansion.

In the context of literary cartography, The Antipodes explores the ethics of mapping a space we have not been to. How did England imagine the "other" and what are the inherent issues with this imagining of the "other"? The idealized idea or map of other spaces presented in travel literature and the description of the Antipode that spurs this intrinsic need for Peregrine to travel and actually experience and interact with these other spaces. Peregrine's "travelling thoughts" (Brome 1.1.131-2) are particularly interesting because it is these very thoughts and fascinations with the exotic that "other" him from the people around him (his family and especially his wife). This fascination prompts his family to say that he needs treatment. Essentially, his fixation on travel "others' him from his homeland and reinforces the importance of belonging to a single nation state.

To Peregrine, the map of the other is one that exoticizes and fetishizes the culture of the "other." However, the space appears very differently to both the audience and actors of the play within the play and the audience watching Brome's Antipodes. The dramatic structure of the play is often described as having a "Russian doll-like structure, which repeatedly blurs the distinction between those who watch and those who do, turning one into the other" (Raman 135). Both the actual audience of the play as well as the fictional one recognizes that the "voyage" undergone within the play is, in fact, a voyage to the playhouse-causing the play to have a self-reflective quality. It is this audiencecentric aspect of the play that makes the audience the authoritative voice of the play as opposed to Peregrinemaking the voice and actions of Peregrine almost laughable (this too is problematic as Peregrine's proto-colonial interactions with the other are seen as a joke not as a serious subject). Most scholars argue that "the emphasis in [the] text is very much Renaissance London in the 1630s" (Jowitt 215). However, even if the authoritative voice of the play is taken to be that of the audience, and the proto-colonial journey of Peregrine is seen as laughable, authority over travel and depicting the "other" (both fictionally and realistically) is under the control of England. By using the "other" for the therapeutic purposes of the audience members and potentially a therapeutic reflection of English society in general still diminishes the exotic as a tool for the benefit of the homeland-a relationship that is fundamentally limited and flawed.

Mapping out the spaces in Brome's Antipodes is a complex matter. For Peregrine, it is an appealing imagining of the exotic that he can first fantasize about and then control and change: "They are an ignorant nation, and have my pity mingled with correction" (Brome 4.3.33-34). However, this "map" is clearly not the same space that the audience members would see being conscious of the performance within the text. The audience members' separation from the actual events of the play are blurred through the metatheatrical elements of the drama, which unquestionably situates English society at the center of the play's intent. However, the drama constructs and endorses a sense of English authority and rule over the "mapping" of exotic spaces both in Peregrine's imagined interactions with the foreign and through the audience's control over the text and representation of the other as a tool for creating and questioning English politics and society.

\section{Performing the Nation: The Modern Implications of Antipodes}

I have already outlined the basis for viewing "otherness" in Brome's Antipodes as a tool to imagine the nation of England, and now I would like to move into a discussion of the global and postcolonial implications the text and the colonial discourse present within Peregrine's interactions with the "other" have within the context of a modern reader/audience. Creating a link between nation formation and the alienation and isolation of the exotic within The Antipodes offers a means in which a modern audience can step back and become critical of their own role in decolonization and also question the inherent effects that globalization has on constructing a sense of nation.

Firstly, the question we must ask is "What does it mean to be part of a nation?" I argue that reading Brome's text as a modern audience can aid in understanding alternative views of nationality and situates the topic of nationhood and culture as something that can be performed. Anderson proposes the following definition for national: "it is an imagined political community-and imagined as both inherently limited and sovereign" (15). Anderson explains that the nation is imagined in the sense that we can never connect with truly everyone within it because of the vastness of the community. However, Antipodes further complicates this definition and portrays nationality as imagined in the sense that it is performative and something that can be chosen and "put-on." In this sense, the word national has taken on a mythical role within our culture by representing an ideal that people can hide behind and is used to construct a sense of euro-centrality, but is not necessarily realistic or 
shared by all. Brome can be read as displaying this definition of a mythical nationality by presenting nationhood as something that is "put-on". It is a way to situate oneself within a national "act" not necessarily to construct a sense of community. By focusing on Peregrine's colonial gaze of the culture and society of the Antipode and the idea that a culture can be "acted" the potentially problematic representation of globalization and nationalism can be explored. Ultimately, I argue that the text questions the gap between nationhood, colonialism, and globalization urging a rethinking of how we imagine the nation in a contemporary era and in doing so questions the proposed "unity" of a nation as well as the ethical implications of characters playing "dress up" with nationhood.

Upon entering the Antipodes, Peregrine enters into what we as the audience know to be the prop-room of the playhouse, but in doing so he views the props and items as intrinsic parts of the exotic space and even goes so far as to dress up and "crown himself King of the Antipodes, and believe he has justly gain'd the kingdom by his conquest" (Brome 3.6.30-31). The fact that nationhood, and in particular exotic nationhood is being represented by elements of performance presents the idea of being a part of a nation as a form of consumerism (the market of drama)something that can be bought, chosen, and controlled. Drawing the reader in through these metatheatrical elements not only alters the way we perceive the text but also asks the reader to locate the themes of the texts within their own consumer-driven lives. It is clear then that the reader plays an intrinsic role in the play and this engagement asks the reader to think about community (both global and national) within their own contemporary setting.

I argue that the text can be taken by a modern audience to ask how society's reliance on technology, and the global connections it brings, complicate the idea of imagining nations. The discussion of nationalism must be expanded not only to political discourse but to also take into account the expanding global economy. Enric Castelló in "Selling and Consuming the Nation: Understanding Consumer Nationalism" defines the term consumer nationalism as "social implications of economic nationalism in the context of everyday life" (559). Consumer nationalism is then a subtype of nationalism that is concerned with economic concepts (branding, marketing, advertising) within the discourse of nationalism. This concept offers an important frame in a modern reading of The Antipodes: To what extent is the nation a tool to "sell"? In the case of the play, the nation of the other can be seen as a tool to enhance and benefit that of the homeland: "Tis a wise nation; and the piety of the young men most rare and commendable... My father, when he goes to school, shall answer" (Brome, 2.9.3337). This passage is taken from the scene where Peregrine finds out old men must go to school in the AntipodePeregrine's comments on the wisdom in this and claims that his father will be soon doing this in the homeland of England (meaning that he will implement a similar policy back at home)-displaying the idea of taking and using the colony for the good of the Empire. Cultural practices and customs in The Antipodes are treated as commodities that can be used to better the "value" of the homeland. The fact that these practices are made up in the play further enhances the performative elements of nationhood. Dressing up and acting a nation urges the reader to become aware of selfcentric uses of nationality and using the diasporic as a tool of both political and corporate gain. It is clear then that in discussing diaspora and nationalism the discourse of economics must be considered.

For a modern audience, The Antipodes presents a "fake it till you make it" mentality to nationhood. It displays the increasing pressure that the global market puts on the idea of selling the nation as a product. When characters dress up or act as certain nations the readers are meant to see it as a façade-imagined. The play shows the potential misrepresentation of people within the construct of nationhood and questions the authenticity of national unity by presenting the idea of nationhood as an act. In doing so, within a play that is heavily metatheatrical, the reader is asked to become conscious of the potential misrepresentations and misuses of both nationalism and transnationalism in politics, business, and even in literature itself. I argue that it is this criticism of space and community that makes The Antipodes a play that is fundamentally concerned with nationalism and colonialism in nature. The idea of "performing" a nation can be read as a means to critique the notion of unified nations. However, it is a means that is not without other problems. Presenting the nation as something that is wearable, or even laughable, diminishes the people of other nations. They are presented as dismissive-as a device to advance the plot and the characterization of the protagonists and English society. The concept of nationhood in Antipodes is one that is not as simple as it first appears; it offers insights and critiques about the changing ideas of nationhood in an increasingly global society, but also raises questions and concerns about the validity of representing people as unified masses. Reading the text in such a manner shows that The Antipodes is literature about nation, but it is also highly critical and aware of the limitations of such a concept and seeks to both dismantle and highlight the prejudices against our understanding of nationalism and the literature, politics, and economics within.

\section{Colonial Discourse-Changing the Other in The Antipodes}

Colonial discourse is a system with which the world can be known by which dominant groups in society constitute the field and truth by imposing specific knowledge, disciplines, and values upon dominated groups. 
This system constructs and endorses a power/knowledge dynamic and constructs an assumed authority of "truth" with those superior in the relationship. Gauri Viswanathan in Mask of Conquest describes the role of English literature in such discourse saying, "English literature-is, in essence, an affirmation of English identity. But that identity is equally split along the lines of actual and ideal selves... [and creates] the Englishman as [the] producer of knowledge that empowers him to conquer, appropriate, and manage" (Viswanathan 14). Viswanathan later goes on to explain that English literature is functioning as a "mask" to hide the economic exploitation that camouflage the material activities of the colonizer. I argue that The Antipodes can be read as displaying and working within this emerging tradition of colonial ways of knowing. Even though the representation of the Antipodes is not oppressing an "actual" culture of the exotic, it still displays and endorses the English author and audience in a position of power both through the colonial discourse used by Peregrine and the placement of English authority over the text.

The language that Peregrine uses while actually in, what he thinks is, the Antipodes displays the notions of colonial discourse that I have laid out previously: "with a purpose to reduce the manners of this country to his own. $\mathrm{H}$ 'has constituted the doctor his chief officer, whose secretary I am to be; you'll see a court well ordered" (Brome 3.6 33-37). Peregrine seeks to infiltrate and change the culture and political workings of the society of the Antipodes-he seeks to reduce them. Not only is Peregrine's interactions with the Antipodes constructing a link between English knowledge and power, but even the doctor's description that the Antipodes are "under" the society they mirror creates the idea that the exotic is inferior-enforcing a power dynamic where the English are very much in control and hold authority. This reading draws heavily on modern post-colonial studies and would not be recognizable to an early-modern audience. However, to modern readers of the play, it can be an important case study to understand and recognize the power/knowledge dynamic that is emerging in global relationships (both fictional and real).

This power dynamic is again shown through the metatheatrical elements of the text. Claire Jowitt in "'To Sleep, Perchance to Dream': The Politics of Travel in the

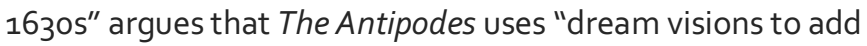
meta-fictional layers to the work, enabling an audience or reader, even a royal one, to explore and think through important political problems from a variety of viewpoints" (264). The article mainly focuses on the applications of such a metafictional world in the context of domestic politics. However, I claim that, for a modern reader, it is equally fruitful to apply such a way of thinking to creating/recognizing the plurality of voices in the context of global relations. There are layers to our relations to other nations and to view it solely from the perspective of the colonizer is truly limited. Although, it does not explicitly offer the perspective of a truly marginalized "other" voice in the text, I argue that it does urge the modern audience or the reader to become aware and critical of the proposed linearity of history (in particular the history of expansion and colonialism) and instead offers multiple frames or "maps" for looking at the same space.

\section{Conclusion}

The multiple maps of space in Brome's Antipodes play very different roles for that of the Early-Modern audience and that of the modern reader. I argue that Brome's text can be seen as a case study to better recognize and understand the mindset surrounding colonial discourse and power dynamics. Criticisms from Anderson and Tally Jr. offer frames for reading travel and travel literature in the text, suggesting new approaches to reading Antipodes through its underlying colonial mindset that is intertwined with the complex metatheatrical elements of the play. Combining the discussion of nationhood with the concept of literary cartography urges the audience to become critical and aware of the descriptions of "place" within the play and how this mapping of geography further complicates the role of imagining nations as well as imagining exotic spaces. Reading Peregrine as a "British" explorer going to control and reform the exotic space of the Antipodes leads quite obviously to a discussion of colonialism and expansionism. By focusing on the ways in which the exotic world is constructed and imagined, the nation as a performance, and the colonial discourse and power dynamics underlying the text I argue that The Antipodes can be read through modern literary theory to better understand and display the emerging difficulties and problems that accompany the developing sense of English nationalism and protocolonialism. In doing so, the text displays the inherent colonial structures that inform and limit the role of both travel literature and the romance genre in "imaging" nations-something that is pivotal to both questioning and understanding the role of the nation in an increasingly global context. 


\section{Works Cited}

Anderson, Benedict. Imagined Communities: Reflections on the Origin and Spread of Nationalism. London, Verso, 1983 .

Brome, Richard, Ed. Haaker, Ann. The Antipodes. University of Nebraska Press, 1966.

Campbell, Mary. "Reviews of Books -- Writing the New World: Imaginary Voyages and Utopias of the Great Southern Land by David Fausett." The American Historical Review, vol. 100, no. 4, 1995, p. 1283.

Castelló, Enric. "Selling and Consuming the Nation: Understanding Consumer Nationalism." Journal of Consumer Culture, vol. 18, no. 4, 2018, pp. 558-576.

Jowitt, Claire. "'To Sleep, Perchance to Dream': The Politics of Travel in the 1630s." Yearbook of English Studies, vol. 44, 2014, pp. 249-264.

Jowitt, Claire. Voyage Drama and Gender Politics, 1589-1642: Real and Imagined Worlds. Manchester University Press: Distributed in the USA by Palgrave, 2003.

Lowe, Eleanor. "Offstage and Onstage Drama: New Approaches to Richard Brome." Early Theatre, 2007, p. 109.

Mckinnis, David. "Therapeutic Travel in Richard Brome's The Antipodes." Studies In English Literature 1500-1900, vol. 52, no. 2, 2012, p. 447-467.

Raman, Shankar. Renaissance Literature and Postcolonial Studies. Edinburgh University Press, 2011.

Tally Jr., Robert T. "On Literary Cartography: Narrative as a Spatially Symbolic Act." NANO, no. 1, 2011, pp. NANO, o1 January 2011, Issue 1.

Taylor, Miles. "The Permeable World: Travel and Carnival in The Antipodes." Exemplaria, vol. 19, no. 3, 2007, pp. 438-454.

Viswanathan, Gauri. Masks of Conquest. Columbia University Press, 2014 